\title{
LOS NEGROS EN LOS CUENTOS DE INDIOS: ACERCAMIENTO INICIAL ${ }^{1}$
}

\author{
Jesús Morales Bermúdez
}

Cuerpo Académico: Sociedad y Cultura en Fronteras

CESMECA-UNICACH

\section{INTRODUCCIÓN}

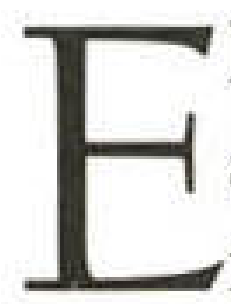

presente trabajo cristaliza el trazo de una inquietud de mi interior, desde los años de mi primer acercamiento a la oralidad y a la emergencia de contadores indígenas en los Altos y sierras de Chiapas. Fue escrito, también, como reconocimiento al Profesor Martín Lienhard de la Universidad de Zürich, Suiza, por valorar en él, además de a una persona de gran calidad humana, políglota admirable, amigo ejemplar, erudito y sabio, a alguien versado en las literaturas marginales y las fronteras entre la oralidad y la escritura en pueblos también marginales al primer mundo. El texto, entonces, intenta una ruta de diálogo con el quehacer de ese estudioso.

Hace años hice la lectura del libro de George Frazer, El folkloreen el Antiguo Testamento. Entre sus páginas llamaron mi atención algunos de los mitos africanos de creación en ellas referidos; el de los shilluks, por ejemplo, en el que, según Frazer:

\begin{abstract}
el creador Juok formó de barro a todos los hombres, pero mientras los creaba iba caminando por el mundo, de modo que en las tierras que ahora ocupan los hombres blancos encontró un barro o arena puro y blanco y con él formó a los hombres de raza blanca. Se dirigió luego a las tierras de Egipto y con el barro de las orillas del Nilo formó hombres de color rojo o pardo. Por último llegó a las tierras de los shilluks, y al encontrar en ellas barro de color negro formó con él los hombres de la raza negra (Frazer, 1981: 20-21).
\end{abstract}

Pensé, entonces, que esta antiquísima tradición, de los pueblos caldeos y mesopotámicos, se construye a partir de dos constataciones: una, que existen razas y culturas humanas y que se diferencian por el color; la otra, que todo hombre al morir se vuelve un puño de barro; ambas nociones generarían la idea de la igualdad humana y de su futuro utópico, siguiendo siempre el razonamiento de Frazer y de los hermeneutas de su tiempo.

Más, ¿qué pasa con los relatos provenientes de otras matrices culturales? ¿Han sido recubiertos por el ánima europea, o perdura algo del ánima anterior? A lo largo de los años he sido sensible a los relatos orale de los campesinos e indios de Chiapas, de México y de otros países y, conociéndolos, los he intercambiado con ellos mismos 
cuando la ocasión se ha presentado. Algunos de esos relatos han llamado profundamente mi atención; los que se refieren al maíz, por ejemplo, o a la adquisición de nuevas posesiones; los de espanto y brujería y, muy particularmente, los referidos a los negros. De estos últimos, me detuve en un pequeño pero significativo número; relatos que se encuentran en transcripción literal o como narración de algún escritor local, entre ellos algunos publicados. Pensé que alguna vez llevaría a cabo un ejercicio de inmersión en sus entretelones y los he mantenido como un corpus a la espera.

El momento finalmente llegó, y pensé en dialogar, en este trabajo, con el estudioso Martín Lienhard, pues por un lado me avenía a trabajar con textos provenientes de la oralidad en la línea de La vozy su huella y, por otro, con referencia a negros en cercanía a O Mar e o Mato, los memorables y hermosos libros que parangonan preocupaciones del mismo Martín. Debo advertir que casi desisto del intento luego de leer la última versión de OMar e o Mato, pues queriendo la cercanía con sus contenidos no hube sino de reconocer la carencia de testimonios y cantos de esclavitud, debido a la rápida mestización entre negros, indios y europeos ocurrida tanto en la entidad como en el país. ${ }^{2}$ Queda sólo una nota referida a una "sublevación» de negros en la región de Palenque, en Chiapas, merced a un informe oficial de algún gobernador. Sin embargo, persisto, pues me convoca la literatura, y en aquella escrita hasta ahora en Chiapas encuentro ecos del ánima negra, tal en relatos canónicos como el cuento «El caballo de la molendera", del sancristobalense Daniel Zepeda, o la novela La simiente del corsario, del cintalapaneco César Coutiño Bezares. Ambos textos se acodan en el habla regional, salpicada de modismos acuñados por negros ladinizados o latinizados, mestizados finalmente en esos que somos los chiapanecos de hoy. Como al azar, un fragmento del cuento ejemplifica:

Por aquel entonces asomó en el Valle un muchachón alto y jornido, trigueñote, con dos ojos escuros y relumbrantes que metian miedo a los hombres y se arrastraban a todas las mujeres; como que era querendón y relabioso, y puntiaba la guitarra y cantaba las peteneras, y repicaba un zapateado que no había quien se la emparjara.

Y como acertó a haber baile en aquella juinca que le digo, que era el santo de la niña, hija de los patrones, todo el día jué de fiestas que retumbaba el llano. Y dende que escureció se puso la marimba en el corredor de la casa grande y se encendieron los juaroles y las luminarias, y acudió toda la gente al llamado de los cuhetes. Y mentras que los amos y sus convidados cenaban, bailaban los mozos con las rancheritas que de todo el Valle se ajuntaron. Y entre todos se lucía Catarino, que ansi se llamaba el muchachón que a saber de onde había venido, rumboso y bien parao aquella noche, con su charro de galones dorados, pantalon 
ajustao, zapatos de vaqueta y su mascada de seda colorada en el pescuezo.

Cuando salieron los patrones, bailaba Catarino con una muchacha, hija del caporal de los vaquerus, la Teresa, la más guapa y remilgaa de todo el Valle, con sus carnes rollizas y temblonas, su nagua colorada, con su camisa blanca de bordaos negros, los brazos desnudos, la cara más bonita que hizo Dios, y aquel mirar que encalabrinaba al hombre más encogido y simarrón.

Con ella bailaba pues, como dije, Catarino, y todos admiraban lo bien emparejaos que iban: él repiqueteando el zapateao, y ella zandungueando retrechera, levantando las naguitas con dos deos de cada mano pa enseñar el piecito y los justanes aplanchaos. Y en cada suspensión de la marimba, Catarino le decía un corrido como un ramo de flores, con todo aquello de lucero de la mañana, dueña de mi corazón y otros tantos efeleoflos que a todos nos dejaban bizcos (Zepeda 1926: 21-23).

El ambiente, como se ve, es de rancho, con vaqueros, fandango y la pasión amorosa rayana en el erotismo, características coloniales atribuidas a los mulatos y negros. Y como en el cuento o en la novela, encontramos voces negras y referencias a la población negra en la poesía de la entidad, particularmente la situada en los Valles Centrales, sitio de presencia mayor de negritud, más allá de la vertiente de negritud que recorriera a la poesía latinoamericana entre los años cincuenta y setenta del pasado siglo. Ya en las postrimerías del siglo XIX, el poeta Rodulfo Figueroa, originario del valle de Cintalapa, escribía en uno de sus poemas:

\author{
Al pie de aquellos árboles copudos \\ como negros fantasmas se agitaban \\ los atletas desnudos \\ que ardorosos se erguian o encorvaban \\ mientras que, presas en sus puños rudos, \\ las hachas, cual relámpagos, brillaban (Figueroa, 1981: 87).
}

Pero a más de la poesía y la narrativa, otros símbolos icónicos, festivos y culturales de negros y mulatos perduran en la entidad chiapaneca tal partes inherentes a su propio ser. La mismísima antigua Ciudad Real, considerada por muchos como asiento de la españolidad durante la Colonia, período en el que más bien sirvió de crisol a la diversidad como ocurre hasta nuestros dias, conserva el templo de San Nicolás de Tolentino, construido ex profeso para la población mulata de la ciudad con su cofradía también mulata; conserva asimismo, en el antiguo barrio de La Merced, asiento colonial de negros y mu- 
latos, y aún se emula en los demás barrios, la festividad de esa advocación con cohetería, carros de anuncio o alegóricos, comparsas desbordadas, muy similares a las de antaño, si nos atenemos a los alegatos hacia el obispo de Chiapas don Carlos Castañón:

\begin{abstract}
[...] los vezinos del Barrio citado de la Merced, sugeridos de ciertos espiritus inquietos amadores del libertinaje, a quienes veo con dolor que seducen mi rebaño y lo que es más lamentable, con el permiso y aún franca aprobación de este Gefe, posponiendo a sus locas diversiones la utilidad espiritual de tener manifiesto a su Divina Majestad en su Barrio, salieron el dia de ayer, según acostumbraron en otros años, enmascarados, vestidos de mugeres los hombres, con grande y repetido estruendo de coetes, de cámaras como llaman, y conduciendo el carro que sacan en paseo en medio del bullicio, de la licencia y de la embriaguez (Cedulario 5, tomo XIII, 17 de febrero de 1800. Archivo Histórico Diocesano).
\end{abstract}

\title{
LOS NEGROS EN CHIAPAS
}

Como en el resto de América, los negros llegaron a Chiapas en los albores de la Colonia. La figura transversal de la historia de la entidad es la de Bartolomé de Las Casas (1474-1566), el fraile dominico a la vez polemista que polémico, sacerdote en La Española y un apasionado encomendero hasta su regreso a España, hacia 1515. Hubo el fuego de los iluminados una vez conmocionado por el sermón que en las vísperas de Navidad pronunciara el otro dominico, Antonio Montesinos, comentando el texto de Juan: «Soy una voz que clama en el desierto» (Juan 1,23), según recuerda el historiador dominico D. M. Chenu (1966: 191-197). ${ }^{3}$

La conversión radical de Bartolomé de Las Casas lo condujo a abandonar su encomienda y a tratar de revertir la acción nociva e injusta de la Colonia y proponerse a sí mismo como defensor de los indios. En el año de 1544 fue nombrado obispo de Chiapas, adonde llegó imbuido de un fervor reivindicativo en favor de los naturales, con la convicción de que esa tierra era idéntica en sus condiciones a La Española por cuanto adoptó, para su propia diócesis, la actitud de Montesinos, atronando contra los conquistadores desde su primera homilia y llegando a los extremos de la excomunión. Amotinados estos en Ciudad Real, ante la que entendían falta de cortesía del prelado y su desconocimiento de la situación local, le reconvinieron alguna alternativa y el obispo concedió el traslado de esclavos negros "porque con ellos se sustentarían en la tierra y dejarían libres a los indios» (Las Casas, 1981, tomo III: 177). Esta gestión se vio coronada con el éxito pues, «entendiendo esto el dicho clérigo [...], alcanzó del rey que para liberar a los indios se concediese a los españoles de estas islas que pudiesen llevar de Castilla algunos negros 
esclavos» (Ibidem: 274). Más aún, él mismo habría de llegar proveído de cuatro esclavos negros, con las debidas licencias de su majestad, según cédula del 13 de febrero de 1544, para el "servicio de su persona y casa» (López Sánchez, 1962: 434).

La literatura regional se ha hecho eco de este desliz, actitud luego corriente en los sucesivos obispos y frailes dominicos, en una de las pocas novelas históricas con que se engalana: Jovel. Serenata a la gente menuda (1992). Luego de narrar la primera homilía del obispo casi con las mismas consideraciones del cura Montesinos - según el relato de Chenu (1966: 191-197) - , luego de referir la proclama de excomunión, los desacuerdos, el motín y detenerse en la disputa entre conquistadores y obispo, ${ }^{4}$ la novela prosigue el alegato esclareciendo la carencia de minas en Chiapas y pone de relieve la acre discusión entre el obispo y su confesor, uno de los doce dominicos que llegaron a Chiapa con él, a causa de la excomunión fulminante y general de aquel sobre los habitantes de la ciudad, injusta a todas luces desde la mirada del confesor (Morales Constantino 1992: 314-330). ${ }^{5}$

El alegato de esta novela, construida desde fuentes primarias y secundarias, es el de decantar el proceso de construcción de la nueva sociedad en los confines del mundo colonial, ausente de inversiones, vías de comunicación, interés de los centros mercantiles, sede simbólica desde la cual construir un alegato moral de larga traza en que el poder eclesiástico se afincó como rector material e ideológico hasta nuestros días. «Ya desde finales del siglo XVI, los dominicos administraban haciendas ganaderas, trapiches y granjerías, y ya desde entonces la provincia era exportadora de cacao, añil, cochinilla, azúcar, cueros de res y ganado en pie» (García de León, 1985: 44). «El despoblamiento, la expansión de las haciendas desde finales del siglo XVI permitirá, particularmente a los frailes dominicos - y no tanto a los particulares cuya economía se encontraba colapsada por la crisis - la importación de esclavos africanos" (González Esponda, 2002: 42). De estos esclavos, a más de beneficiarse los dominicos en sus fincas, se beneficiaron también los obispos de Chiapas, en general también domini$\cos$, para su servidumbre doméstica. Fue el caso, por ejemplo, aparte de fray Bartolomé de Las Casas, de los obispos fray Andrés de Ubilla, fray Tomás Casillas o fray Juan Bautista Álvarez de Toledo, franciscano él.

Al mentorazgo de sus prelados, los habitantes de Ciudad Real y de las Provincias de Chiapa y Soconusco en general se avinieron a hacerse de esclavos negros para los trabajos en sus estancias y, sobre todo, en sus hogares, debido a que:

...por la población negra que llegaba a Chiapas habia que pagar, de alli que no fuera extraño que recibiera un trato privilegiado en relación con el indigena [...] el trabajo más pesado recaía en este último [...]. La recuperación relativa de la fuerza de trabajo indigena llevó a los dueños de haciendas a preferir el trabajo de estos frente 
al de los esclavos negros. Para 1778 la población india ocupaba un lugar prioritario en las haciendas frente al de los negros, mulatos e incluso mestizos, quienes iban siendo desplazados hacia otras actividades económicas (Soriano, 1993: 405).

Incluso, cuando a principios del siglo XIX se pensó en impulsar de nuevo la introducción de esclavos negros, la respuesta de los españoles radicados en Ciudad Real fue en el sentido de que "no eran necesarios los negros esclavos", a causa de que "no simpatizaran con los negros y sus posteriores mezclas por su genio altivo y opuesto a la sujeción» (González Esponda, 2002: 60-61), razón insuficiente para no integrarlos en las milicias cuando hubo necesidad.

Una muestra censal del comportamiento poblacional hacia 1778, promovida por el obispo Francisco Polanco, destaca la presencia de 6456 negros y mulatos en las Provincias de Chiapa y Soconusco, a la par de 2365 europeos, 5158 mestizos y castizos y 60416 indios y naboríos. De ellos, aproximadamente 1109 habitaban en las haciendas, en contraparte de 109 europeos, 224 mestizos y castizos y 2138 indios y naboríos (Ibíd: 57-59). «El mayor número de afromestizos se encontraba en Ciudad Real, probablemente porque no sólo radicaban ahí los ocupados en el servicio doméstico y en la milicia, sino también los libres, cuyo número aumentaba rápidamente» (Ibid:: 57), fenómeno este que ocurrió desde las primeras décadas de la Colonia. Sin embargo, los había en por lo menos 26 curatos de las Provincias con números no necesariamente escasos, aun cuando con diferencias porcentuales en relación a otros grupos poblacionales o castas, como se los llamaba en el período colonial. Por ejemplo, en Cintalapa, un total de 518 negros y mulatos significaba $48 \%$ de su población total, o, en Tonalá, un total de 2115 negros y mulatos significaba 59\% de su población, mientras que los 830 de Ciudad Real significaban 10\% o, los 408 de Tapilula, 15\%. Al paso del tiempo, en poblados como estos últimos particularmente o en el Soconusco, donde hubo negros o mulatos en forma significativa, "[...] efectuaban los trabajos más rudos - como el corte de caña-, o eran mozos de servicio doméstico que gozaban de algunos privilegios. Otros comprahan su libertad y se convertían en caporales y vaqueros, enseñoreándose sobre los indios» (García de León, 1985: 50 passim), y llegó a darse el caso de que se hicieran dueños de fincas.

Al parecer, «sólo en Chamula, Zinacantán, Oxchuc, Cancuc y Guaquitepec, el 100\% de la población era indígena» (Soriano, 1993: 396-397). Pero tampoco estos poblados dejaron de resentir los flujos físicos y culturales de aquellos pobladores, a pesar de los límites coloniales a la cohabitación en ellos de F 'lación externa. Es el caso, por ejemplo, de su presencia en los carnavales y el profundo peso de la hechicería y el nahualismo. Llama la atención cómo el relato oral, ahora transcrito y publicado, más cercano a una rememoración de la historia, provenga precisamente de alli: 
Cuando los negros llegaron a la región de los Altos [...] la gente al enterarse de su llegada a la región no salía de su casa por las tardes, mucho menos caminaba lejos [...]. Los negros fueron muy malos, asesinaban a todas las personas que encontraban en los caminos o en sus trabajos [...] no sólo mataban sino que también agarraban a las mujeres y las violaban, mientras que a las señoritas las llevaban a sus cuevas [...] aprovechando la oscuridad de la noche. Cuando amanecía los negros estaban felices, descansando en sus cuevas tomando un sueño tranquilo [...] (Gómez Gutiérrez, 1998: 136).

\section{Presencia de los negros en los Cuentos}

Las cuestiones corrientes de hechicería y nahualismo persistentes hasta hoy no se entenderían sin los contactos culturales entre negros y mulatos e indios. Es frecuente en los relatos indígenas el recurso a la transmutación de personas en animales con el propósito de hacer mal a alguien o provocar confusión. Dondequiera se escucha aquello de que el espíritu de una mujer abandonaba su cuerpo en el lecho conyugal mientras su marido dormía para sobrevolar por el pueblo, hasta que éste se dio cuenta y pidió consejo; hubo quien le dijera que aquello era hechicería y que cuando tal ocurriera echara sal con oraciones al cuerpo para que el espíritu no pudiera reencarnar; hizo en esa forma y la mujer se perdió llorando y maldiciendo entre la noche. Otros cuentos existen en que se comenta que un hombre se convirtiera en culebra, perro o caballo; en algún momento alguien mataba al animal y con sorpresa se miraba cómo a la misma hora fallecía el cristiano. Se intenta con los ejemplos señalar cómo ya la propia fabulación es "cosa de negros".

Casos similares a los anteriores narra la historiadora Dolores Aramoni para el período colonial: en el juicio del mulato Nicolás Santiago (1722), indios y mulatos lo acusan de:

brujo, hechicero y encantador [...] en un cerro que está vecino al pueblo de Xiquipilas, tiene un ídolo en cuya figura adora y reverencia al Demonio; ofreciéndole dones y sacrificios, y que asi mismo le han visto muchas personas a deshoras de la noche transformado en figura de horroroso perro, amedrentando todo el pueblo de Xiquipilas y sus contornos (Aramoni, 1992: 191-192).

La dimensión de hechicería y nahualismo recubre el imaginario de indios y mestizos por igual, pero mira su origen en las tradiciones africanas, tan arraigadas ya que cualquiera las confiesa como tradición propia, en actitud similar a la observada frente a la marimba, instrumento musical de origen africano pero calificado como tradición cultural de Chia- 
pas. Una clave de esos imaginarios la hallamos en la obra del obispo Francisco Núñez de la Vega, quien en un documento escribe:

[...] en muchos pueblos de la provincia de este obispado tienen pintado en sus repertorios Siete Negritos para hacer divinaciones y pronósticos correspondientes a los siete dias de la semana comenzándola por el viernes a contar como por los siete planetas los Gentiles y al que llaman osla huntor [...] le tienen pintado en silla y con hastas en la cabeza como de carnero. Tienen los indios gran miedo al negro porque les dura la memoria de uno de sus primitivos ascendientes de color etiopioso que fue gran guerreador y crudelisimo según consta por un cuadernillo historial antiquísimo que en su idioma escrito para en nuestro poder (Núñez de la Vega, Expediente 66: 1, Archivo Historico del Estado).

En otro momento, el dicho obispo abunda en torno al cuadernillo, sus implicaciones, descripción de elementos y festejo, diciendo entre otras cosas lo siguiente:

Porque en instrumentos escritos en idioma índico, y por declaraciones de diferentes reos, me consta y ha constado que las provincias de todos los obispados de la Nueva España están infestadas, y muy vivas en ellas y practicadas las ceremonias de esta secta supersticiosa de naguales, y gravísimos maleficios [...].

[...] ha entrado en mi poder, en que tenían el pacto con el Diablo, cuatro libros del Tepanaguaste [...] y con algunas cláusulas de lengua hebrea -en que por modo de canto explicaban y daban noticia a qué parajes y sitios de cuevas, montes, cerros, etcétera, habia de ir a ejecutar las supersticiones [...].

Y la noticia de esta cueva constó de un cuadernillo historial en que el autor decía que cierto gentil llamado Hutubón, alio nomine Botán, fabricó a soplos la cueva de Hueguetán, y que alli estaba un gran tesoro en unas tinajas tapadas [...] este tesoro de las efigies y relatos de los gentiles primitivos alude el canto y baile del Tepanaguaste, que se hace con unas tinajas tapadas. Yo he quitado in totum este baile, y quemado casi ciento y cincuenta tepanaguastes con más de cuatrocientas flautas y otras tantas tinajuelas que eran ministriles de este baile -y le llaman del Palo Hueco-, que indubitablemente tengo averiguado ser uno de los principales con que se da culto al Demonio (Núnez de la Vega, 1988: 237-238).

Las consideraciones del obispo refieren flautas y tambores en actos de hechicería, instrumentos a través de los cuales podemos retraer a los negros como los responsables de 
expandir hechicería y nahualismo entre los indios. Desde ese enfoque, veamos características comunes a los negros en algunos de los relatos de los mismos indios. Por principio, iquién o cómo son los negros? Muchos dicen: «El negro, el sombrerón, la llorona, la yegualcíhuatl, etcétera, son de la misma familia, ya que ambos molestan y espantan a las gentes» (Gómez Gómez, 1989: 82). Su naturaleza, pues, es la maldad, la chocarrería.

Otros relatos que cuentan encuentros con el negro dicen:

Los negritos son unos seres que se parecian a los ladinos, (o mestizos bien vestidos), sólo que más chaparritos y bien negritos, que gustaban fumar mucho puro. Sin embargo eran muy forzudos, que no se podia comparar sus fuerzas con las de los hombres normales. Tan fuertes eran que hasta un toro levantaban al aire, además eran invulnerables a todas las armas terrenales. Como están hechos de acero, no se le podía dar muerte (Anónimo, 1989). ${ }^{6}$

La dificultad para morir, su capacidad de resistencia resultan emblemáticas. Aun así, algunos textos afirman la vulnerabilidad de los negros vía la decapitación; otros, al contrario, los muestran invulnerables como no sea por el poder del rayo entrándoles por el ano. Sabiéndose invencibles, los negros gustan de probar sus fuerzas y, particularmente, de apostar la cabeza con los indios. Pero, según los relatos, de esta confrontación con frecuencia salen victoriosos los que no son negros, es decir, los indios. Y no puede ser de otra forma, pues los relatos sugieren que en la pelea se ponen en juego los atributos de la cultura: la superioridad de aquella que vence y la inferioridad de aquella que resulta vencida. De allí el diálogo:

¿Eres hombre de verdad y completo?/ Si, yo soy hombre completo ¿y tú?/ Pues yo también soy un hombre completo y de verdad./ [... Aqui vamos a ver quién es el verdadero hombre [...] se sentaron alrededor de aquella piedra grande redonda que es la mesa del negro, que las sillas eran troncos de madera que al sentarse se iban rodando. Que los utensilios de los negros eran: para comer tenía jicaras negras, ya que era lo que robaba en las casas y los demás eran de pura piedra y troncos de árboles [...] él se alimentaba de carne de animal crudo porque no la azaba (Gómez Gómez, 1989: 84).

Aparte de ese desdén frente al ajuar (primitivo) y alimento (crudo) de los negros, los relatos indios los consideran inferiores por su incapacidad de producir milpa, signo primordial de la civilización; por eso roban comida y bienes: porque no tienen cultura. Y es que los negros llegaron de fuera, de Guatemala tal vez. Se diferencian notoriamente de los hombres verdaderos, a quienes gustan de hacer chocarrerías y maldades, 
sobre todo por el robo de las mujeres, su carencia de respeto hacia las formas de vida establecidas. ${ }^{7}$ Procuran rondar las casas por las noches para aprovecharse de las mujeres que se levantan a orinar; o se acercan por las madrugadas para hurgar si quedan solas, o asaltan a las que caminan solas. De allí que fuera prohibido por los viejecitos caminar muy temprano o muy tarde, particularmente en los meses de Todos Santos y particularmente en la región de Oxchuc, donde la niebla baja hasta los suelos que a unos cuantos pasos no se distingue lo que se encuentra delante de uno y es entonces cuando dicen que los negritos salen a rondar por los caminos, los campos, las milpas, en busca de las muchachas que van por el agua o a ver la milpa, o a cortar ejotes, jilotes, elotes, en esos meses cuando los sembradíos se encuentran en producción.

Una vez con la muchacha a cuestas, la conducen a sus cuevas, porque en las cuevas de los cerros agrestes, hondas y oscuras viven los negros. Como son parientes de la noche no conocen los beneficios del sol; tampoco los del fuego: su cercanía les quema. De alli que su alimento sea diferente al de los hombres, no cocido, de aspecto y sabor desagradables. Las cuevas les procuran a los negros resguardo y en ellas, merced a su dominio sobre brebajes y elíxires, dominan la voluntad de las mujeres, cohabitan con ellas y alcanzan la procreación de otros negros, en escaso tiempo. En general las mujeres no desean este tipo de relación con los negros, aunque se dan casos en que sí, y sostienen actitud ambivalente ante sus hijos. No tienen, sin embargo, mayor alternativa de libertad y sufren, muy a pesar del interés de los negros que se preocupan por agradarlas y complacerlas en todos sus caprichos. Buscan fugarse de sus cuevas o alcanzar la muerte. Así, se excluyen de los negros y los excluyen de su vida, en exclusión que alcanza también a sus hijos, pues mueren al nacer o en edad pequeña.

Pero si las mujeres rechazan a los negros, cuando alguna de ellas ha sido raptada por un negro sufre también el rechazo de su consorte, si lo tiene, así haya vuelto con disposición amorosa hacia él o se haya acercado apenas a su casa. Un hijo del negro, que es también negro, es señal de su cohabitación con él y funge como estigma. El contacto contagia, como en el caso de la K'ux ak'al, la mujer que comía carbón por las noches mientras su marido dormía y que al ser sorprendida por éste fuera abandonada, porque el marido "no quería vivir con una mujer hechicera", alguien identificada con el mundo de los negros, de lo negro. Lo mejor, entonces, es no acceder nunca a la presencia de los negros y, en caso de que en el mundo aún los hubiere sueltos, preferible buscar su exterminio combatiéndolos con el arma mortífera: el fuego, bien en su forma directa, bien en su grado extremo de rayo y trueno. En general, el rayo, el trueno, el torbellino acompanan a quienes luchan contra los negros. Un ejemplo al azar: 
Iban todos dispuestos y bien preparados para acabar con los negros. Traían más hombres fuertes con ellos, los hombres rayos y torbellinos. Después de retirar a las mujeres que quisieron salir, en ese momento comenzaron a trabajar todos los rayos y torbellinos, quemaron la cueva; por eso hoy dia todavia se ven las huellas: partes quemadas y ahumadas en las entradas de las cuevas. Así acabaron con todos los negros (Gómez Gutiérrez, 1998: 142).

Este relato narra un ataque por sorpresa: llegar a la cueva y prenderle fuego; pero hay batallas de carácter épico que suponen travesías y retos mayores. El «Cuento de dos hombres rayos y un negrito", por ejemplo, narra la aventura de dos mensajeros, enviados por las autoridades de Tenejapa y Cancuc hacia Comitán en un período de dificultad en los caminos a causa de los espantos provocados por un negrito. A su vuelta, cansados ya, solicitaron posada en el pueblo de Oxchuc, en donde el dueño de la casa los alojó por un día comentándoles la dificultad de una permanencia mayor, pues al día siguiente llegaría el negrito para llevarse a su hija. Los hombres arguyeron no tener miedo y prometieron buscar la forma de acabar con el negrito. Muy temprano, al día siguiente, se presentó el negrito por la hija del casero. Los hombres rayos convinieron un duelo con él y se enfrascaron en una lucha a muerte. El negrito se preparó transformándose en rayo; los hombres rayo en "barras de fierro bien rojo como fuego". Primero uno de los hombre se metió bien en el culo del negrito. Es cuando tronaban los dos arriba: trommm, trommm, trommm, así tronaba el rayo en el cuerpo del negrito. Entre iguales se daban el trueno de rayo arriba, se bajaban, se subían, se cansó el hombre rayo. Sin darle tiempo al negrito, el otro hombre se mete en el culo del negrito con truenos de rayo, y fue muerto el negrito, tanto truenos de rayo (Anónimo, 1989).

Las autoridades agradecieron a los hombres rayos, les pidieron tomar mujeres de su pueblo; ellos declinaron, pues tenían las propias, pero al final accedieron; tomaron mujeres, procrearon: «Así fue que dejaron dos niños rayos y los hombres rayos se fueron para sus tierras, que eran mensajeros» (Ídem). Los dos niños rayos sirvieron también a las autoridades de Oxchuc yendo a Guatemala a traer la madre del tesoro de Guatemala. En su hazaña, por tres veces diferentes enfrentaron a tres distintos negritos, esta vez no con rayo sino apostando las cabezas, de modo que tras preservar las propias acumularon en su morral las tres cabezas de los negritos vencidos, con las que sc presentaron ante la autoridad de Guatemala, que los encarceló por un momento, pues siendo rayos rompieron la cárcel; se ordenó fusilarlos y «es cuando los niños sólo lo topaban con sus sombreritos las balas» (Ibídem). Provocaron un incendio y se marcharon con la madre del tesoro de Guatemala. A su vuelta a Oxchuc, «los niños querían tambores, músicas, flautas, inciensos y flores. Los tres pueblos no obedecieron, ellos creyeron que eran mentiras» (Ibidem). 
Despechados, los niños rayos decidieron no dejar la madre del tesoro en Oxchuc, sino en la ciudad de México, por eso «actualmente México es rico, grande, porque allá pasó la madre del tesoro de Guatemala» (Ibídem).

Hasta aquí, sintéticamente, el decir de los cuentos indigenas sobre el negro o los negros. Pero su presencia no concluye alli. Huelga recordar los diferentes carnavales de los indígenas en que aparecen los negros al lado de los capitanes y las maruchas, en series de comparsas que remedan los festejos de la sociedad colonial. A veces, como en los carnavales de San Juan Chamula y de San Pedro Chenalhó, el negro se viste con la identidad del mono o max, apariencia que lo vincularía con otra serie de relatos relativos a lo selvático o salvaje, metáfora también del negro. En la región del Soconusco, el poblado mestizo de Tuxtla Chico celebra la festividad de San Pedro Mártir, en su representación de santo negro con un machete incrustado en la cabeza, en el mes de abril, cercanías del carnaval, con comparsas de vaqueros y peones, adultos y jóvenes, pintados como negros, quienes reparten, entre los concurrentes, dulces regionales a base de coco.

\section{Comentarios AL CALCE}

El etnocentrismo propio a los indios y el promovido entre ellos por las autoridades tanto coloniales como republicanas y religiosas, los muestra refractarios a todo afán de mestización aun cuando en la realidad participen de mestizaciones biológicas y culturales de manera dinámica. A la fecha, son harto diferenciables las etnias entre sí, construcciones coloniales que son. Ello, aunque organizaciones políticas y no gubernamentales las afirmen en unidad identitaria particular, diferenciables de "los otros", o «distintos»: lo ladino o mestizo y su mundo, en la medida de querer identificarlos con los descendientes de quienes lograron la conquista e impusieron otra costumbre. ${ }^{8}$ Los negros, en tanto sustitutos de la fuerza de trabajo en las haciendas dominicas, conservan, en los cuentos, las características casi zoológicas de la esclavitud a que se vieron sujetos.

A diferencia de los españoles, soldados de a caballo que llegaron con dominio, los negros fueron traídos de fuera, de Guatemala dicen los textos, identificando Guatemala con el sitio de poder colonial a que estuvieron mayormente sujetas las Provincias de Chiapa y Soconusco; sitio, también, en que las funciones de capataces en fincas y plantaciones recaían en pobladores de color, a quienes se consideraba de mayor fuerza y bravura. A los soldados se les otorga la misión de guardar la entrada al sitio de donde fueron traídos los negros y con ellos el mal, Guatemala, en donde gobierna el capitán español, y son auxiliados en ello por los indios. Pero con frecuencia los soldados se alían a los negros en contra de los indios, como en la sublevación tzeltal de 1712, en que tanto los dominicos de Chiapa de los indios como el Alcalde Mayor de 
Tabasco y la Capitanía General de Guatemala enviaron negros entre sus milicias para combatir a los sublevados. La dicha misión, entonces, es semejante, a la concedida a los guardianes del mundo subterráneo de los mitos tradicionales: de manera similar a como en el mundo subterráneo sólo es posible transportarse luego de sortear peligros arduos que pueden conducir a la desgracia, ir hacia Guatemala que es como decir ir al lugar de los poderes, implica correr el riesgo de perder la vida. Tal es el sentido de apostar la cabeza con los negritos. Si se vence, se gana el tesoro, la vida, el bienestar, lo mismo que se gana el sitio de la tranquilidad en el mundo subterráneo, una vez sorteados los peligros.

Como en el resto de América, cupo también a los primeros negros en Chiapas allegarse mujeres para su satisfacción y reproducción un tanto a su arbitrio, pues en su mayoría llegaron sin parejas, o bien se volvieron cimarrones a salto de mata, o bien no gustaban legalizar sus relaciones, vía el matrimonio monógamo, que la Iglesia «no solamente legisló sobre el tiempo y separación de los esclavos, sino también sobre los días y horas en que les estaba permitido a los negros cohabitar» (González Esponda, 2002: 77) y buscaba su cumplimiento. ¿Dónde poder hacerlo? En Ciudad Real, claro, pero sobre todo en los pueblos de indios y, desde luego, al cobijo de la oscuridad. Estos asaltos generan la mitología de los negros como señores de la noche, invencibles, muy fuertes, como lo demuestran en el trabajo, con poderes extranaturales que les permiten volar y con poderes de seducción, vestidos como mestizos y con puros, tentación no necesariamente escasa para las mujeres, o bien, campeando los atributos de lo sexual, ya que preñan inmediatamente a las mujeres y alumbran hijos en forma por demás pronta.

En otro tipo de relatos testimoniales diferentes a los de negros, los de monterías por ejemplo, se cuenta la disponibilidad de las mujeres lacandonas hacia los chicleros, los fuertes venidos de lejos, con quienes cohabitaban siempre con ciertos cuidados, siempre en ausencia de sus maridos a quienes aquello molestaba, pues aun siéndoles de su conocimiento no lo podían impedir: ni modo de permanecer todo el tiempo en casa, ¿de qué iban a vivir? Algo similar debió ocurrir en aquellos tiempos de la Colonia. Y, como hemos señalado, pronto comenzó el mestizaje. Sin embargo, los trasiegos de la identidad, la disputa en torno a las bondades culturales y la calificación hasta moral de los diferentes rasgos o la ponderación de las costumbres, desde la Iglesia, condujeron a rechazar del seno de las comunidades indias a los hijos de india y negro y a negar la posibilidad de sobrevivencia de esos niños. ¿En qué sociedad tendrían cabida? Y como en el caso de los niños, el mismo mecanismo operaba hacia las mujeres que han tenido trato carnal con los negros: se las rechaza, no sea que al usarlas de nuevo den la sorpresa de nuevos negros. Se las conjura, entonces, a la soledad y a la muerte. No importa que apenas hayan probado la vida con los negros: «Ya comieron carbón», 
dice un relato. La sociedad exige que se aindien o se vayan, que se afirmen indios, que no mulatos o negros, por exigencias de la clasificación en castas de esa sociedad y la prohibición a cohabitar entre indios. ${ }^{9}$

A propósito del carbón, llama la atención la similitud que los textos confieren a los entes negros con el carbón. Por principio, debe recordarse cómo el carbón se elabora en cuevas u hornos de la tierra, y cómo los relatos refieren que los negros habitan en tales sitios. Debe recordarse también cómo los mitos de origen sitúan al fuego y sus guardianes al centro de las cuevas.

En términos de las cuevas, la simbolización es aún mayor: «En cuevas se realizaban rituales ígneos de renovación de periodo", dice el historiador Sheseña (2005: 318). Y en la cueva de Joloniel, municipio de Tumbalá, por ejemplo, en sus paredes se encuentran glifos y figuras de negros fechadas hacia el año 520 a. C., simbolizando esa renovación y los poderes de la tierra, una cueva que atrae a los noctámbulos, borrachos y pendencieros.

Desde esas rememoraciones, los negros no son el fuego, pero viviendo en las cuevas no se benefician del fuego como los humanos, más bien se queman como el carbón. Los negros son carbón. Se explica que no mueran con los golpes de hacha cuando apuestan la cabeza (el tronco de árbol se vuelve leña o carbón en trozos), pero sí con el rayo al interior de su cuerpo, con el fuego. Vueltos fuego sí benefician a los hombres, a la comunidad: su ceniza abona la tierra y, ya vueltos tierra, como en su origen, como en el relato de Frazer, aquellos que no saben cultivar pueden generar el maíz, origen y sustento. La diferencia radical entre los hombres se encuentra en el origen: los negros y todos los pueblos de Occidente se cuentan en sus mitos como creados de barro por un hacedor; los pueblos de Mesoamérica, formados con el maíz. La posibilidad de encuentro de unos y otros se halla allí: en el esfuerzo de florecer el maíz, en la tierra, en la cultura.

Los negros y lo negro, según los relatos, también vuelan, llevan la fertilidad entre sus manos por los aires: a las mujeres. Vueltos tal, se tornan bendición. ${ }^{10}$ Pues iqué es volar negro y procreador sino mutar en nube negra, en lluvia? Las nubes con lluvia, los negros lluvia son causa de bendición, de dicha. Hasta en bienaventuranza se vuelven, como lo dicen algunos relatos de la región.

\section{ANEXo}

\section{"CUENTO DE DOS HOMBRES RAYOS Y UN NEGRITO"}

A la autoridad de Tenejapa le llegó un mensaje de Comitán. Para contestar el mensaje, tuvieron que citar dos hombres rayos que ellos pueden enfrentar peligros en camino. 
En los años antepasados no se podía cruzar los caminos en la noche, entonces la autoridad de Tenejapa y Cancuc, opinaron bien las dos autoridades para que llegue bien el mensaje a Comităn. Los dos hombres mensajeros llegaron bien a Comitán. Al regreso de Comitán los dos hombres rayos se anochecieron en el camino con mucho hambre y sed por tanto que habian caminado. Los dos hombres rayos se sentaron a la orilla del camino para pensar qué iban a hacer, si iban a dormir en el camino o en una casa cerca de la Iglesia de Oxchuc.

Entonces los dos hombres rayos mensajeros entraron a prestar casa, lo hablaron el dueño de la casa cerca de la Iglesia, le dijieron los dos hombres rayos que sí podían quedar una noche nadamás, porque viene a espantar un negrito: Porque mañana la vienen a traer mi hija, porque el negrito la está llevando por turno los niños.

Entonces contestaron los dos hombres: No la tengo miedo el negrito, dijieron los hombres, mañana lo veremos como acabar el negrito. Muy temprano se levantaron los hombres rayos y la dueña de la casa, también llegó muy temprano el negrito, es cuando tocó la campana de la Iglesia: tin-tan, tin-tan, tin-tan, como ya todas estaban levantadas los que estaban adentro de la casa.

El negrito seguía tocando la campana de la Iglesia. Los dos hombres rayos se prepararon bien como se iban a convertir trueno de rayo. Al momento llegó el negrito. Es cuando dijo:

-Buenos días compadre. Contestaron los dos hombres rayos:

-Buenos días negrito. Dijieron los dos hombres: Qué quieres aqui.

El negrito dijo:

- Vengo a llevar su hija del señor.

Al escuchar la palabra del negrito el hombre rayo le dijo al negrito:

-Antes que la lleves la hija del señor hagamos un trato con los tres, afuera de esta casa.

Dijo el negrito:

-iPor qué afuera?

-Si -dijieron los hombres rayos-, vamos a pelear dos contra uno.

Dijo el negrito:

-Estoy de acuerdo.

El negrito se preparó a bolar corno rayo. También el hombre rayo se convirtió de una barra de fierro bien rojo, como fuego, que era el hombre rayo. Se metió bien en el culo del negrito. Es cuando tronaban los dos arriba: trommm, trommm, trommm, asi tronaba el rayo en el cuerpo del negrito. Entre iguales se daban el trueno de rayo arriba, se bajaban, se subían, se cansó el hombre rayo. Sin darle tiempo el negrito, el otro hombre se mete en el culo del negrito con truenos de rayo, y fue muerto el negrito, tanto truenos de rayo. 
Al frente del pueblo fue el pleito. Había mucha gente que lo vieron. Los principales de ese pueblo trajieron muchos regalos para los hombres rayos. Los principales dijieron:

Gracias que nos ayudaron.

Los hombres rayos no aceptaron los regalos. Entonces la gente opinaron que se formaran las muchachas bonitas y lo dijieron los hombres rayos:

Escojan una muchacha cada uno - para que dejaran sus hijos rayos para ese pueblo. Los hombres dijieron que no, porque ellos tienen sus mujeres, ya después aceptaron escoger sus mujeres. Al siguiente le nacieron un hijo cada uno; así fue que dejaron dos niños rayos y los hombres rayos se fueron para sus tierras, que eran mensajeros.

Despues vino un mensaje de Guatemala para la autoridad en Oxchuc. La autoridad en Oxchuc citó a los niños rayos, a quienes iban a dejar la contestación del mensaje. Los principales autoridades compraron dos morrales y dos machetes para cada uno de los dos niños rayos.

Los niños se fueron a Guatemala; cuando van encontrando un negrito en el camino. Dijo el negrito:

-Aqui no hay paso, si quieren pasar primero la cortaremos la cabeza que tienen. Contestaron los niños:

Está bien.

El primer niño lo puso su cabeza en camino, que no se cortaba la cabeza del niño. Los niños rayos le dijieron al negrito:

-Póngalo tu cabeza negrito, para cortarlo también. Dijo el negrito:

Está bien. Es cuando con un machetazo se cortó la cabeza del negrito.

Los niños rayos siguieron caminando; es cuando encuentran otro negrito ya en medio camino de Guatemala. Dijo el negrito:

Si quieres pasar aqui se pone primero la cabeza en el camino para cortarlo.

Los niños dijieron que si.

El segundo nino rayo puso su cabeza en camino, no se cortaba. Entonces los niños le dijieron al negrito:

-Póngalo tu cabeza negrito, para cortar también. El negrito dijo que si, con un machetazo se cortó la cabeza del negrito.

Los niños rayos siguieron caminando, cuando se asoma otro negrito ya cerca de Guatemala.

Decian los niños rayos:

-QQue hacemos? Ya no entra en nuestro morral las cabezas del negrito.

Dijo el negrito: 
-Aqui no hay permiso para entrar a Guatemala, si quieren entrar la cortaremos una por una sus cabezas.

Aceptaron los niños rayos, ninguno de los dos niños se cortó sus cabezas. Los ninos le dijieron al negrito:

-Ahora te toca negrito.

Cuando el negrito le cortaron con un machetazo en el cuello y lo pusieron en el morral la cabeza del negrito.

Así pudieron entrar a Guatemala. Los niños rayos se presentaron con el coronel. Dijo el coronel:

¿Qué traen en sus morrales? Contestaron los niños rayos:

Son cabezas de los negritos. Es cuando ordena el coronel:

Soldados, quítenlos los dos machetes y dos morrales, al cárcel los niños rayos.

Los niños tuvieron un rato al cárcel, como son rayos lo rompieron con rayo la cárcel. Decia un soldado:

-Ya salieron los niños, le dijieron al coronel.

El coronel volvió a dictar orden que lo fusilaran a los niños, los soldados fueron a fusilar a los niños, es cuando los niños solo lo topaban con sus sombreritos las balas. Los soldados vieron que no morían los niños, y tuvieron miedo, le fueron a avisar el coronel que ya no habian más balas.

Se viene el coronel.

¿Qué cosa quieren niños?

Los niños dijieron:

Queremos la madre del tesoro de Guatemala.

El coronel dijo que no, es cuando venia incendio cerca a donde estaban los soldados. El coronel dijo que la llevaran la madre del tesoro de Guatemala, como vio que venía el incendio.

Antes que regresaran los niños, mandaron a avisar el pueblo de Oxchuc, Tenejapa, Cancuc, para que ellos fueran a alcanzar la madre del tesoro de Guatemala, y los niños querian tambores, músicas, flautas, incensos y flores.

Los tres pueblos no obedecieron, ellos creyeron que era mentiras. Los niños rayos y con la madre del tesoro de Guatemala venían con cantos de mucha alegría.

Los niños rayos dijieron:

Como nadie vinieron a alcanzarnos, pasaremos de paso en Oxchuc. Y los niños se fueron a México para vivir. Como no llegaron a alcanzarnos, dijieron los niños, no quedará Central de México Oxchuc, ni lo dejaremos la madre del tesoro de Guatemala, lo llevaremos hasta más arriba de Oxchuc. 
Por eso se fundó México cerca de Cuernavaca y actualmente México es rico, grande, porque allá pasó la madre del tesoro de Guatemala.

\section{"El NEGRITO Y LOS INDIGENAS"}

Aquí vamos a narrar algo que se antoja increible, pero según los que lo vieron y supieron de este acontecimiento aseguran que fue cierto y verídico. Tan así que hasta la fecha los pobladores de mi comunidad ai me lo recuerdan como si estuviera fresco y de reciente acontecer esta leyenda.

En mi pueblo natal, Oxchuc, la gente, por lo improductivo de sus tierras y muchas veces, también, por causa de los efectos de los fenómenos meteorologicos de la naturaleza, como son: el huracán, las heladas, los granizos, las sequias, etcétera, que al parecer se ensañan con los sembradíos de los indigenas, azotándoles en forma cruel y despiadado lo poco que podría constituir el sustento vital de sus familiares, por esta razón casi nunca cosechan sus productos. Por tal motivo emigran como braceros en busca de algún alivio económico a las fincas cafetaleras del Soconusco; solo que para llegar a estas fincas cafetaleras tenían que trasladarse a pie y realizar largas caminatas durante varios dias, sorteando mil peligros, como la presencia de asaltantes, de animales peligrosos, como son los tigres, los leones, las víboras venenosas, etcétera, que según el decir de los propios caminantes, abundaban estos animales; porque en aquellos tiempos se atravesaban aún grandes extensiones de montanas en donde casi no se miraba la claridad de la luz del sol y que se padecian, además, de los peligros que ya hemos mencionado. A cada paso los sustos que provocaba la presencia de los monos que se divertian con cierta crueldad al espantar a los viajeros, tirándoles ramas secas o frutas de los gigantescos árboles donde se columpiaban alegremente estos hermosos primates.

Mi difunto padre, que en paz descanse, por haber quedado huérfano desde pequeño, pronto se vio en la penosa necesidad de viajar con mucha frecuencia, como bracero, a las fincas cafetaleras del Soconusco, razón por la cual conocía a muchos enganchadores y a muchas fincas. Tanto lo conocían a él que, cuando viajaba, le daban la comisión de conductor. La gente le conocían como el doctor, pero por no saber pronunciar la palabra conductor, y en las fincas trabajaba, siempre, de caporal, porque dominaba con destreza y habilidad los quehaceres de la cafeticultura.

Don Isidro Vázquez, que así se llamó en vida mi padre, un día salió de Kistoljá, Oxchuc, Chiapas, para encaminar hacia Jovel a su hermano y a un compadre suyo, para que se contrataran como braceros para algunas de las fincas cafeta- 
leras del Soconusco, con un señor de nombre don Tacho. Este señor, dicho sea de paso, era conocido por muchos pueblos indigenas y desde luego era amigo de don Isidro; por eso, con el engancharía a su hermano y a su compadre.

Tiempo atrás la gente indigena que viajaba a distintos lugares para comprar o vender algunos de sus productos, recogian noticias de que en las iglesias, en las montañas, en las cuevas, acostumbraban vivir los Negritos; unos seres que se parecian a los ladinos, solo que más chaparritos y bien negritos, que gustaban fumar mucho puro. Sin embargo eran muy forzudos, que no se podia comparar sus fuerzas con las de los hombres normales. Tan fuertes eran que hasta un toro lo levantaban al aire, además eran invulnerables a todas las armas terrenales. Por este motivo las personas, para viajar, siempre lo hacian en grupo, por temor a ser atacados en cualquier momento y nunca caminaban separados uno del otro; sobre todo en los tiempos de mucha neblina y lluvias. Durante los meses de noviembre y diciembre el peligro tomaba mayores dimensiones. Generalmente cuando se aproximaba la celebración de las fiestas de Todos los Santos era prohibido por los viejecitos caminar muy temprano o muy tarde, porque por estos meses, y particularmente en la región de Oxchuc, baja hasta los suelos que a unos cuantos pasos no se distingue lo que se encuentra delante de uno y es entonces cuando dicen que los negritos salen a rondar por los caminos, los campos, las milpas, etcétera, en busca de las muchachas que salen a traer el agua o a ver la milpa, cuando van a cortar ejotes, jilotes, elotes, porque por estos meses es cuando los sembradios se encuentran en plena producción tierna.

Cuentan los mayores que en San Cristóbal, especialmente en la iglesia de Guadalupe, miraban en la torre, y atrás de la imagen de la misma virgen de Guadalupe, pasearse los Negritos, de brillantes ojos como los de los gatos. Es bueno aclarar que estos Negritos no atacaban en cualquier tiempo, sino solamente cuando se acercaban las festividades de San Andrés, que por cierto se efectúa el 10 de noviembre, y según los viejecitos, este Santo es el protector de los Negritos, por ser, además, el Santo de la neblina y la llovizna. Estos Negritos eran el azote de los pueblos y de los caminantes; en todas las ocasiones se presentaban bajo el aspecto de un mestizo bien vestido, con un cigarrillo o puro en la boca, y, que le decian a sus victimas:

-Quiubole amigo!

Se asustaba el caminante. El Negrito, esto le producía enorme placer. Volvía gritar, diciendo:

iViva, vival Diciendo esto se alejaba volando, dejando solamente un penetrante olor a ajo.

Tal como lo hemos relatado, un día, por los meses de noviembre o diciembre, le 
sucedió a don Isidro lo siguiente: Que después de haber conseguido contrato con don Tacho, para su hermano y para su compadre y haberlos visto partir para otras tierras, se quedó en San Cristóbal a pasar la noche, y como le dejaron unos centavos para que comprara algunas cosas para las esposas de los viajeros, se le ocurrió salir a caminar un rato por las calles de Jovel y desgraciadamente le cayó la noche y como esta bella población aún no contaba con alumbrado eléctrico muy pronto quedaban sus calles en completa obscuridad. Cuando él iba subiendo por las calles empedradas de Guadalupe, iqué sorpresa!, le salió al paso el consabido personaje, el susodicho Negrito, vestido elegantemente de tela negra y como de costumbre, de inmediato le dijo:

- iQuiubole amigo!

Diciendo esto, que de su bolsa sacó un frasco conteniendo un líquido extraño que enseguida le derramó en su cabeza. El efecto del líquido desconocido no se hizo esperar, al momento sintió pesadez en todo su cuerpo y no tuvo fuerzas para enfrentarse al enemigo, que de por sí era invencible.

Aqui vamos a comentar algo con relación a la creencia de lo sobrenatural de los indigenas, pero que creen a pie juntitos como una verdad indiscutible en la vida real de ellos; la existencia de entre ellos personas con nagual, que se come el alma a sus parientes y vecinos. Pero contrario a estos brujos también había personas con espíritus buenos y fuertes que actuaban como guardianes de las personas que no poseían almas con el poder del bien o del mal. Así como los espíritus del mal tenían contacto con los demás espíritus malos de otros pueblos, también los espíritus buenos y fuertes mantenían alianza con otros pueblos.

Los espiritus malos podian presentarse bajo las formas de diversos animales, como son: los perros, pájaros, tigres, leones, víboras, etcétera. En cambio los espiritus buenos se presentaban bajo las formas del rayo, el viento, piedras, hachas, machetes, el fuego, etcétera.

Como el Negrito era hombre hecho de acero, no se le podia dar muerte, y cuando alguno de los poderosos guardianes del bien intentaba hacerle frente, era derrotado de inmediato. Cuando se retaban apostando sus cabezas, su cuello del Negrito rebotaba el hacha y en cambio el del contrincante volaba de un solo hachazo su cabeza; lo que siempre ocurría cuando había lugar a algún duelo. Hasta que un día los espiritus poderosos de los indios se sintieron profundamente ofendidos y molestos por las derrotas que sufrían a cada paso, fue cuando entonces decidieron reunirse para discutir en grupo sobre la estrategia a seguir para vencer al enemigo. Así empezó una acción conjunta y simultanea para explorar la estructura de su cuerpo del dichoso Negrito, acción que dio como resultado 
que al Negrito le localizaron su talón de Aquiles, que era vulnerable, dicho sea con perdón de nuestros lectores, por el ano. Ante tal descubrimiento, fue fácil planear la destrucción del poderoso Negrito.

Es aquí que don Isidro, cuando ya se encontraba totalmente abandonado por su energía corporal, su espíritu fuerte voló, para pedir auxilio con los principales de Tzontajal (Amatenango del Valle) y los de Alanch en (Venustiano Carranza).

Al darse cuenta el Negrito de que su victima ya no podía oponer resistencia fisica, según la versión que conocemos hasta la fecha, lo cargó con un enorme lienzo negro, solo que el se equivoco, ya que su víctima no había perdido la conciencia y se daba cuenta de cuanto ocurría a su alrededor.

El Negrito empezó a volar y se fue con rumbo a Tuxtla Gutiérrez, que allá era el destino del valioso cargamento. Era para colocar como alimento de las grandes construcciones de los edificios de la capital. Pero sucedió que ya cerca del río de Chiapa de Corzo lo alcanzaron sus amigos de Amatenango del Valle y Venustiano Carranza y se cclocaron estratégicamente en su cuerpo del Negrito, de tal suerte que cuando accionaron sus poderes, no lastimaran al compañero a rescatar. El rayo, que era el más poderoso, penetro por el orificio natural del Negrito. Pegó un grito fuerte y estallo en mil pedazos el temible NEGRO, en las orillas del río Grijalva.

Don Isidro, dicen que le llevó varios dias de camino para regresar a su casa; sus cosas todas se perdieron, excepto el dinero que lo llevaba bien guardado entre sus ropas.

\section{Notas}

' Una primera versión de este trabajo fue publicado en Annina Clericci y Marilia Mendes, (coords.), 2007, Demárgenes y silencios Homenaje a Martin Lienhard, Iberoamericana, España.

2 "Con relativa prontitud, dice la estudiosa Silvia Soriano, la linea de color que separaba a una casta de otra se fue haciendo cada vez más tenue, con lo que la sociedad dividida en castas fue perdiendo el matiz que la sostenía; los hijos de mulatos con otras razas dejaban de ser negros a la vista del fraile encargado de contarlos y muchas veces se les colocaba en una columna a la que tal vez no correspondían. Zambos con indias, pardos con mestizas, mulatos con indias, etcétera, se diluyeron con el tiempo perdiendo presencia los negros" (Soriano, 1993: 405), a más de que desde finales del siglo XVII los descendientes de negros o mulatos fueron adquiriendo su libertad.

${ }^{3}$ El historiador dominico D.M. Chenu narra el suceso: «El sermón, pronunciado ante la minoría dirigente de la primera ciudad española fundada en el Nuevo Mundo, escandalizó e indignó a sus oyentes. Montesinos clamaba con voz de trueno: "Para haceros conocer vuestras faltas contra los indios he subido a este púlpito, yo, la voz de Cristo que clama en el desierto de esta 
isla; debéis, por tanto, escucharme, no distraídos, sino con todos vuestros sentidos y con todo vuestro corazón, para oír esta voz, la más extraordinaria que habéis oído jamás, la más áspera, la más severa, la más temible que jamás hayáis pensado oir... Dice que estáis en estado de pecado mortal, que vivís en este estado, que moriréis en él, a causa de vuestra crueldad hacia una raza inocente. Decidme, iqué principio, qué justicia os autoriza a mantener a los indios en una tan horrorosa esclavitud? ¿Con qué derecho habéis declarado una guerra tan atroz contra esta gente que vivía pacificamente en su país?... ¿Por qué los dejáis en tal estado de agotamiento, sin alimentarlos suficientemente, sin preocuparos de su salud? Porque el trabajo excesivo que les exigís, los abruma, los mata. Mejor dicho, sois vosotros los que los matáis, queriendo que cada día os traigan su oro... ¿Por ventura no son hombres? ¿No tienen una razón, un alma? ¿No tenéis el deber de amarlos como a vosotros mismos?... Estad seguros de que, en estas condiciones, no tenéis más posibilidades de salvación que un moro o un turco".

"Después de esto, Montesinos, con la cabeza erguida, abandonó precipitadamente la iglesia, entre los murmullos de los administradores y de los colonos, estupefactos e irritados. Éstos fueron en masa a la residencia del gobernador, para protestar contra el sermón, en el cual veían una negación escandalosa de la soberanía real sobre las Indias. Enviaron también una delegación indignada al convento, para exigir excusas y una desautorización. El superior, $\mathrm{Pe}$ dro de Córdoba, a quien no impresionó la amenaza de hacer expulsar al religioso agresivo, les afirmó que Montesinos había hablado en nombre de la comunidad de los dominicos. Prometió, no obstante, que Montesinos volvería a tratar del tema en su sermón del otro domingo. Ante lo cual, los colonos se retiraron, convencidos de que habían obtenido una satisfacción. "Contaban con una explicación, y la noticia corrió rapidísimamente; así, el domingo siguiente, la mayoría de los notables espanoles se apretujaban en la iglesia. Montesinos subió al púlpito, y tomó como tema este texto poco tranquilizador: "Soporta todavía por un instante mis palabras, y yo te diré lo que tengo que añadir en nombre de Dios". En vez de hacer rectificaciones sutiles de su primer sermón, se cebó con nuevo ardor en los colonos, advirtiéndoles que, en adelante, los religiosos les negarían la confesión y la absolución, como si fuesen ladrones de camino real. Y que podian escribir a España lo que quisieran y a quien quisieran".

${ }^{4}$-Ellos [los indios] vienen a servir al Señor, tronó el obispo. Y en mayor excomunión estáis cayendo al insultar a los ministros del Altísimo. Su misión es salvar vuestras almas y librar de vosotros las de esos pobres a quienes vosotros habéis venido a oprimir con cargas superiores a sus fuerzas. -Digo yo, le interrumpió sin miramientos Francisco de Velasco, dejad que vuestros frailes vayan a los montes a cumplir su misión. Que ellos les den a los indios el alimento del alma y los hagan cristianos, como nos dicen que lo han hecho en Tezulutlán. Pero alzar ciudades y sacar de la tierra la comida del cuerpo es labor nuestra que cumpliremos, mal que os pese. -iSeguro!, gritaron los amotinados. 
-Pero no con la sangre de mis indios, clamó transformado el obispo.

- ¿Ahora ya son vuestros?, se oyó que rezongaba con sorna una voz al fondo de la habitación. -Son de Dios, que es lo mismo. Mas esperad. Yo os propongo algo que puede ayudaros a vosotros y salvar a estos pobres. ¿Por qué no compráis esclavos negros?

Estalló una sonora risotada, y en el tumulto apenas se entendía lo que decían.

-iYa salió el judío!

-iVendenegros!

-iLos negros no son de Dios?

Pero el prelado no se daba por vencido, y a señas y a gritos pedía que se calmaran para continuar. -Los negros son más fuertes que los indios, a quienes obligáis a trabajar en cosas que nunca han conocido. Vuestras minas y vuestras plantaciones exigen brazos hechos a eso (Morales Constantino, 1992: 314-315).

5 Después del refrigerio, el prelado decidió que era hora de dormir. Se tumbó al lado de fray Rodrigo, que permanecía tercamente sentado bajo su palmera.

-iLeísteis con cuidado la carta que escribí a su majestad?, interrogó el obispo antes de cerrar los ojos.

-La lé́, replicó el fraile, y me causó gran preocupación y pesar.

- ¿Por qué?, exclamó levantándose bruscamente el superior y alzando las manos casi en ademán de golpear al fraile.

Por entre las palmas había ya asomado una luna grande y amarillenta. Lejos, muy lejos jugueteaban los monos aulladores, persiguiendo a los venados del llano como entre carcajadas. Cerca roncaban los esclavos negros, rendidos por la carga del camino.

-¿Por qué?, repitió el obispo.

-Porque mentís, tronó con tonos desconocidos la furibunda voz de fray Rodrigo.

- ¿Cómo os atrevéis?, replicó el obispo sentándose apresuradamente.

-Miente Vuestra reverencia, prosiguió fray Rodrigo, cuando exagera las vejaciones cometidas por nuestros hermanos. Miente cuando no para mientes en las buenas ordenanzas de los ayuntamientos a favor de los indios. Miente cuando acusa a todos por igual, sin catar las diferencias que van de unos a otros. Miente vuestra reverencia cuando acusa por la necesidad de triunfar en las discusiones de la Corte. Miente cuando muestra las apariencias de poderes que no competen a la dignidad de su reverencia. Miente cuando excomulga a su grey por tener esclavos, cuando su reverencia los tiene echados aquí en este monte del Señor.

Se callo fray Rodrigo, asustado de aquel tremendo sermón lanzado contra su propio superior. Se callaron los monos y hasta los grillos, y la luna se recató detrás del lienzo de una nube pasajera. El obispo se desató lentamente el cinto, se quitó la capucha y empezó a ciliciarse en penitencia, rompiendo con el ritmo de sus azotes el sagrado silencio del palmar (Morales Constantino 1992: 314-315).

" El "Cuento de dos hombres rayos y un negrito" que se cita en este apartado y en otros apartados del texto, está firmado por "Anónimo", y llegó así a uno de los concursos de "Cuentos y 
relatos indigenas" que a lo largo de los años ochenta y noventa convocó el CIMECH-UNAM (ahora PROIMMSE-IIA-UNAM). He revisado los siete volúmenes en que se publicaron los trabajos concursantes y en ninguno aparece; lamentable exclusión, quizás por extravío. En virtud de la utilidad que pudiera revestir, lo incluyo en Anexo, al final del artículo y la bibliografía. Lo mismo vale para el cuento "El negrito y los indigenas», igualmente Anónimo, si bien fue presentado con el seudónimo "El Chapulín Colorado".

${ }^{7}$ Un relato ejemplar en este sentido sería el de Domingo Gómez Gutiérrez, "Los negros en los Altos de Chiapas”, en Cuentos y relatos indigenas, Vol. 7, México, UNAM \& UNACH, 1998, pp. 135 - 145).

${ }^{8}$ El cuento de Gómez Gutiérrez (vid. Nota 6), ejemplifica convergencia y disparidad en el rubro.

${ }^{9}$ (González Esponda, 2002:71) recuerda la existencia de Cédulas Reales de prohibición de cohabitación de españoles, mestizos, negros y mulatos en pueblos de indios, y el posterior ordenamiento a que se cumplan: "que todos los españoles, mestizos, mulatos y negros de cualquier edad y calidad que sean salgan luego de los pueblos de indios y que se vayan a vivir y residir a los de los españoles como está mandado", y coloca la referencia: AGI, expediente 395, ff. 25-27, microfilm, rollo 3, IEI-UNACH, San Cristóbal de Las Casas, Chiapas.

${ }^{10}$ Véase, por ejemplo, el relato de Manuel Morales López: "En medio de una nube se fue la virgen”, en Cuentos y relatos indigenas, Vol. 2-3, México, UNAM y Gobierno del Estado de Chiapas, 1994, pp. 259-263.

\section{Bibliografia}

Aguirre Beltrán, Gonzalo, 1989, La población negra de México. Estudio etnohistórico, Fondo de Cultura Económica, México.

Anónimo, 1989, Cuento de dos hombres rayos y un negrito, sin publicar.

Anónimo (El Chapulín Colorado), 1989, El negrito y los indigenas, cuento sin publicar.

Aramoni, Dolores, 1992, Los refugios de lo sagrado. Religiosidad, conflicto y resistencia entre los zoques de Chiapas, Consejo Nacional para la Cultura y las Artes, México.

Chenu, Marie-Dominique, 1966, El evangelio en el tiempo, Estela, Barcelona.

Coutiño Bezares, César, 1958, La simiente del corsario, Editora Latino Americana, México.

De Las Casas, Bartolomé, 1981, Historiadelas Indias, tomos I-III, Fondo de Cultura Económica, México.

Duvalier, Armando, 1962, Poesía negra americana (Breveantología), Revista ICACH, núm. 8, Enero - Junio, Instituto de Ciencias y Artes de Chiapas, Tuxtla Gutiérrez, Chiapas.

Encino Gómez, Marcos et al.,1989-1998, Cuentos y relatos indigenas, vol. 1-7, UNAM, México.

Figueroa, Rodulfo, 1981, Poemas (Colección Libros de Chiapas), Gobierno del Estado de Chiapas, México. 
Frazer, George, 1981, El folklore en el Antiguo Testamento, Fondo de Cultura Económica, México.

García de León, Antonio, 1985, Resistencia y utopia: Memorial de agravios y crónicas de revueltas y profecías acaecidas en la Provincia de Chiapas durante los últimos quinientos años de su historia. Ediciones Era, México.

Gómez Gómez, Antonio, 1989, "Cuento sobre el negro", en Cuentos y relatos indigenas, vol. 1, UNAM, México.

Gómez Gutiérrez, Domingo, 1998, "Los negros en Los Altos de Chiapas", en Cuentos y relatos indigenas, vol. 7, UNAM, México.

Gómez Hernández, Juan, 1994, “El negro”, en Cuentos y relatos indigenas, vol. 4, UNAM, México.

Gonzáles Esponda, Juan, 2002, Negros, pardos y mulatos: otra historia quécontar, Colección Biblioteca Popular de Chiapas, Gobierno del Estado de Chiapas, Tuxtla Gutiérrez, Chiapas.

González, José Luis y Mónica Mansour, 1976, Poesía negra de América, Era Ediciones, México.

González Sánchez, María, 1994, "El cazador y la hija del rayo", en Cuentos y relatos indigenas, vol. 5, UNAM, México.

Lienhard, Martín, 2003, La vozy su huella, Juan Pablos y UNICACH, México.

Lienhard, Martín 2005, OMar eo Mato. Histórias da Escravidao, Kilombelombe, Luanda.

López Sánchez, Hermilo, 1962, Apuntes históricos de San Cristóbal de Las Casas, edición personal de su autor, México D. F.

Morales Bermúdez, Jesús, 1989, Antigua Palabra. Narrativa indigena ch'ol, Plaza y Valdés y UNICACH, México.

Morales, Heberto, 1992, Jovel. Sernata a lagentemenuda, Porrúa y Gobierno del Estado de Chiapas, México. Morales López, Manuel, 1994, “En medio de una nube se fue la Virgen”, en Cuentos y relatos indigenas, vols. 2-3, UNAM, México.

Núnez de la Vega, Francisco, 1988, Constituciones diocesanas del Obispado de Chiapa, Nueva edición preparada por María del Carmen León Cázares y Mario Humberto Ruz, UNAM, México.

Recinos, Adrián, 1979, Popol Vuh, Fondo de Cultura Económica, México.

Santis Hernández, Lorenzo, 1998, "Dos caminantes y el negro", en Cuentos y relatos indigenas, vol. 7, UNAM, México.

Sheseña, Alejandro, 2005, "El significado del grupo de pinturas 2 de la cueva de Joloniel", en Anuario 2004 CESMECA, Universidad de Ciencias y Artes de Chiapas, Tuxtla Gutiérrez, Chiapas.

Soriano Hernández, Silvia, 1993, Losesclavos africanos y su mestizaje en la provincia de Chiapas, Colección Textos para abrir el milenio, Instituto Chiapaneco de Cultura, Tuxtla Gutiérrez, Chiapas. Zepeda, Daniel A., 1926, Cuentos regionales, Sin noticia editorial, México. 